\section{FedUni ResearchOnline \\ https://researchonline.federation.edu.au}

Copyright Notice

This is the peer-reviewed version of the following article:

Masud, M. F., Chattopadhyay, G., \& Gunawan, I. (2019). Development of a Risk-Based Maintenance (RBM) Strategy for Sewerage Pumping Station Network. 2019 IEEE International Conference on Industrial Engineering and Engineering Management (IEEM), 455-458.

https://doi.org/10.1109//EEM44572.2019.8978633

Which has been published in final form at:

https://doi.org/10.1109/IEEM44572.2019.8978633

Copyright ( 2019 IEEE. Personal use of this material is permitted. Permission from IEEE must be obtained for all other uses, in any current or future media, including reprinting/republishing this material for advertising or promotional purposes, creating new collective works, for resale or redistribution to servers or lists, or reuse of any copyrighted component of this work in other works. 


\title{
Development of a Risk-Based Maintenance (RBM) strategy for sewerage pumping station network
}

\author{
M. F. Masud, G. Chattopadhyay, I. Gunawan \\ Maintenance \& Reliability Engineering, School of Science, Engineering \& Information Technology \\ Federation University, Churchill, Australia \\ (g.chattopadhyay@federation.edu.au)
}

\begin{abstract}
Industries have been facing ever-increasing challenges to do more with less under ongoing budget constraints. They are pushing the boundary by challenging the OEM recommended maintenance intervals and relaxing or tightening based on where it is needed. This is also evident in water sector where industries are trying to do targeted maintenance based on balancing costs, performances and risks. The unexpected failures, the down time associated with such failures, the environmental overflows and, the increasing maintenance costs are major challenges all wastewater reticulation and distribution networks. Industries have been working hard to increase the availability of equipment and reduce the life-cycle cost without compromising safety and environmental targets. Risk-based maintenance (RBM) strategy is useful for allocation of maintenance resources where first allocation occurs to the highest risk item and progressively allocated till it reached budget limits. This paper is based on findings from a study covering 186 sewerage pumping stations of Townsville Water in North of Queensland in Australia. This study covered identifying the critical subsystems and mitigating the risks of failure of those subsystems. Implementation of risk based maintenance strategy was useful in further enhancing reliability and reduction of maintenance costs.
\end{abstract}

Keywords - Risk-based maintenance, Reliability, Availability, Maintenance cost management, Life Cycle Cost (LCC).

\section{INTRODUCTION}

Industries have been pushing the boundary set by Original Equipment Manufacturers (OEM) for recommended maintenance intervals and trying to do more with less under ongoing budget constraints. Water sector is trying to apply targeted maintenance based on future directions in line with ISO55000 for balancing costs, performances and risks.

Studies on Preventive Maintenance Intervals and Replacements for decisions for good asset management are covered in [1, 2], Kumar [3] and Chattopadhyay and Kumar [4]. Research shows a strong relationship between maintenance practices and the occurrence of major accidents. Studies show that profitability is influenced by availability of the equipment.

Backlund and Hannu [5] discussed maintenance decisions based on risk analysis and an effective use of resources. A comparative study based on Hydro power plants led authors to emphasise the need of homogenised quantitative risk analysis.

A holistic, risk-based approach to asset integrity management was discussed in [6]. It is based on combining risk assessment and risk-based decision-making tools to achieve corporate and regulators objectives.

Most of the studies are either quantitative or semiquantitative. Khan and Haddara [7] proposed a comprehensive methodology for risk-based inspection and maintenance of HVAC system. The equipment is prioritised based on total risk (economic, safety and environmental) and was applied to an ethylene oxide production plant $[8,9,10]$.

Probabilistic risk assessment (PRA) as a tool for maintenance prioritisation is used by Vesely, Belhadj, and Rezos [11].

A risk based opportunistic maintenance (RBOM) model considering failure risk is proposed in Jinqiu $\mathrm{Hu}$, Laibin Zhang [12] for significantly reducing the maintenance costs.

Application of risk-based maintenance have improved the system reliability in the past few decades [13, 14]. Lowest possible Life Cycle Cost (LCC) strategies for asset management (operation, maintenance and capital expenditures) is being embraced for sewerage pumping stations all over the world and is used in this study for sewerage pumping station network of Townsville Water.

CAPEX $=$ Cost of overhauls + Cost of replacements.

Capital investment options are ranked using various tools including Net Present Worth (NPW).

OPEX $=$ Cost of operations + Cost of Inspection + Cost of Maintenance.

Life Cycle Costs (LCC) analysis is based on the entire life of the asset and not just based on CAPEX or OPEX.

Life Cycle Costs $($ LCC $)=$ Design and Procurement Cost $(\mathrm{P})+$ Capital Cost $(\mathrm{C})+$ Lifetime Operating Costs $(\mathrm{O})$ + Lifetime Maintenance costs + Lifetime Maintenance Costs (M)+ Lifetime Plant Losses (L) + Plant Disposal Cost (D)

Fig.1 shows a typical STP asset in the network. 


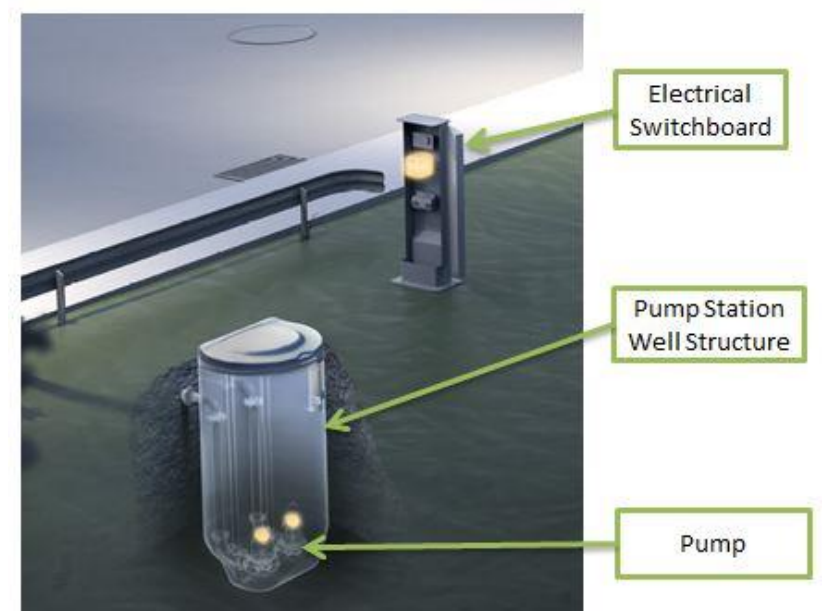

Fig. 1.Sewerage Pump Station Layout

\section{METHODOLOGY}

Risk-based maintenance (RBM) methodology reduces life cycle cost and following methodology is proposed:

Defining the scope: This project covers 186 wastewater pumping stations in Townsville. Each pumping station is classified into subsystems based on the asset hierarchy. Subsystem are comprised of pumps, valves, pipework, switchboards, telemetry and structures. Failure data for individual equipment or asset for all the pumping stations were obtained from the CMMS (Technology 1). These failure data were analysed for the Mean Time Between Failures (MTBF).

Fault Tree development: Fault tree is constructed. Each intermediate event of this fault tree was subsequently extended to basic events and analysed accordingly. These intermediate events were used in the risk assessment of different failure scenarios.

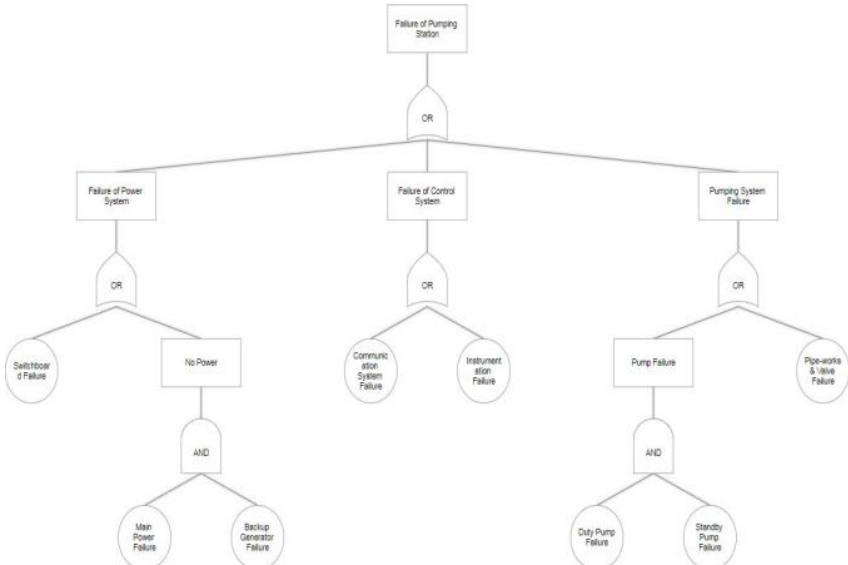

Fig. 2. Fault Tree

Failure Consequence Analysis: Organisation has an "Enterprise Wide Risk Management Framework". The Water \& Waste part of this framework was used to perform the risk assessment. For each failure event a consequence rating was given in 3 different contexts, Social / Community, Economic and Environmental. These were further broken-down into detailed levels in the Consequence Matrix.

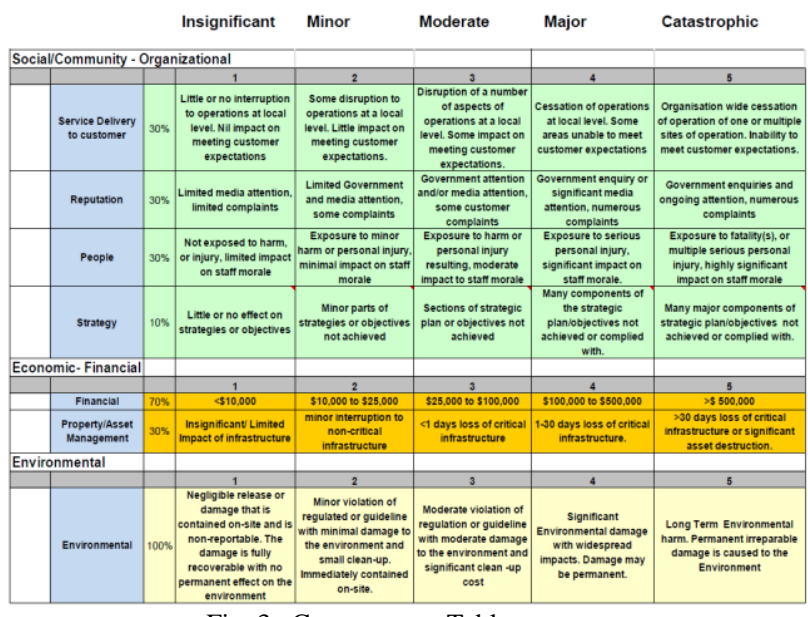

Fig. 3. Consequence Table

Determination of Likelihood: A qualitative assessment is performed to determine the Likelihood of failure of pump stations using failure data from CMMS and operational record and Townsville Water's Enterprise Wide Risk Management Framework Guideline.

\begin{tabular}{|c|c|c|c|}
\hline Level & Classification & $\begin{array}{c}\text { Chance of } \\
\text { Occurrence }\end{array}$ \\
\hline A & Almost Certain & $>90 \%$ & $\begin{array}{c}\text { May occur in most circumstances, say a number of times } \\
\text { a month }\end{array}$ \\
\hline B & Likely & $50-90 \%$ & May occur in most circumstances, say about once a year \\
\hline C & Moderate & $20-50 \%$ & May occur once every 2-5 years \\
\hline D & Unlikely & $1-20 \%$ & $\begin{array}{c}\text { The event may not yet have occurred, but could occur at } \\
\text { some time, say once in 10 years }\end{array}$ \\
\hline E & Rare & $<1 \%$ & May occur in exceptional circumstances \\
\hline \multicolumn{2}{|c|}{ *Refer to Townsville City Council's enterprise wide risk management framework for latest version of likelihood table. }
\end{tabular}

Fig. 4. Likelihood Table

Risk Ratings: The combination of failure consequence and likelihood resulted in four possible types of risk ratings: Low Risk, Moderate risk, Significant Risk and High Risk.

\begin{tabular}{|c|c|c|c|c|c|c|}
\hline \multirow[t]{2}{*}{ Risk } & \multicolumn{6}{|c|}{ Consequence } \\
\hline & & Insignificant & Minor & Moderate & Major & Catastrophic \\
\hline Likelihood & Grading & 1 & 2 & 3 & 4 & 5 \\
\hline Rare (1) & 1 & & & & & \\
\hline Unlikely (2) & 2 & & & & & \\
\hline Moderate (3) & 3 & & & & & \\
\hline Likely (4) & 4 & & & & & \\
\hline $\begin{array}{l}\text { Almost } \\
\text { Certain (5) }\end{array}$ & 5 & & & & & \\
\hline \multicolumn{7}{|c|}{ Legend } \\
\hline Low Risk & & Moderate Risk & & nt Risk & & \\
\hline
\end{tabular}

Fig. 5. Risk Rating Matrix 
Risk Evaluation: Based on the overall risk rating, a risk evaluation is performed along with development of a risk mitigation strategy for risks that do not meet the evaluation criteria and risk treatment plans are developed.

Maintenance Planning: Subsystems that failed to meet the acceptable risk criteria were studied for a maintenance program that will reduce the risk. Maintenance levels and the maintenance interval are determined based on target to reduce the risk. The maintenance type was determined depending on the level of risk and expected reduction of the failure rates and or predicting the potential failures.

For all subsystems with High Risk and Significant Risk, Preventive Maintenance, Predictive Maintenance and Critical Spare analysis was conducted. Root Cause Analysis (RCA) was recommended for MTBF below threshold level. The Preventive Maintenance interval is proposed to 3 Monthly if MTBF was below 182 days, 6 Monthly Preventive Maintenance if MTBF was more than 182 days but less than one year, Yearly if MTBF was greater than one year. For Mechanical subsystems with Low and Moderate Risk ratings, Run To Failure (RTF) along with Rotable Spare was recommended if MTBF was more than one year, Yearly Preventive Maintenance if MTBF was between 100 days and one year, 6 Monthly Preventive Maintenance with RCA was recommended if MTBF was less than 100 days. For Instrumentation and Communication subsystems with Low and Moderate Risk ratings, 2 Yearly Preventive Maintenance was suggested if MTBF was more than one year, Yearly Preventive Maintenance if MTBF was between 200 days and one year, 6 Monthly Preventive Maintenance if MTBF was between 100 days and 200 days. RCA was suggested if MTBF was less than 100 days.

\section{RESULTS}

Risk assessment is performed and it is observed that out of 558 subsystems majority of them has risk ratings of either Low Risk or Moderate Risk. Very few subsystems had Significant Risk and one subsystem showed High Risk (Low Risk - 45.9\%, Moderate Risk - 50.7\%, Significant Risk $-3.2 \%$ and High Risk $-0.2 \%$ ).

Fig. 6 shows the Risk Rating analysis for three subsystems.

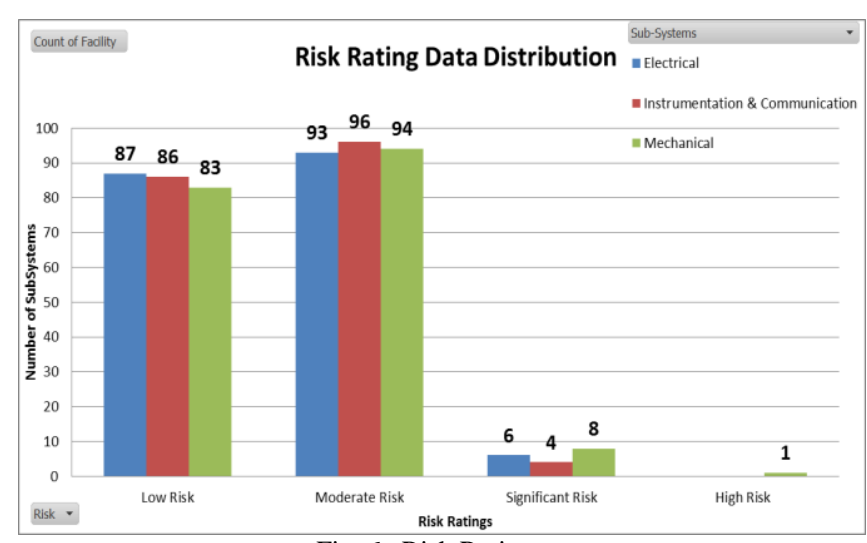

Fig. 6. Risk Rating

MTBF of Major Subsystems are analysed and presented in Table1.

Table 1

MTBF of High Risk Pumping Station - Major Subsystems

\begin{tabular}{|l|r|r|r|}
\hline Facility & $\begin{array}{c}\text { MTBF - } \\
\text { Mechanic } \\
\text { al (days) }\end{array}$ & $\begin{array}{c}\text { MTBF - } \\
\text { Electric } \\
\text { al (days) }\end{array}$ & $\begin{array}{c}\text { MTBF - } \\
\text { Instrumentatio } \\
\text { n \& } \\
\text { Communicati } \\
\text { on (days) }\end{array}$ \\
\hline $\begin{array}{l}\text { Pump Station } \\
\text { 10B }\end{array}$ & 680 & - & 1,360 \\
\hline Pump Station 2A & 489 & 186 & - \\
\hline Pump Station 33 & 83 & 453 & 680 \\
\hline Pump Station 9K & 170 & 227 & 680 \\
\hline $\begin{array}{l}\text { Pump Station } \\
\text { C36A Station }\end{array}$ & 136 & 38 & 680 \\
\hline $\begin{array}{l}\text { Pump Station } \\
\text { C6B }\end{array}$ & 7 & 255 & 227 \\
\hline $\begin{array}{l}\text { Pump Station } \\
\text { K16C }\end{array}$ & 31 & 233 & 158 \\
\hline $\begin{array}{l}\text { Pump Station } \\
\text { M2B }\end{array}$ & 183 & 38 & 252 \\
\hline Pump Station S6 & 18 & 286 & 453 \\
\hline $\begin{array}{l}\text { Pump Station } \\
\text { Wb7 }\end{array}$ & & & \\
\hline
\end{tabular}

The Maintenance Strategy is divided into two types, Primary Strategy which includes either Preventive Maintenance or RTF and Secondary Strategy which includes, Predictive Maintenance, Critical Spares, Rotable Spares and RCA. Table2 shows output of analysis grouped in to 5 different groups of items in STP system. 
Table 2

Maintenance Strategy

Group1

\begin{tabular}{|c|c|c|c|c|c|c|c|}
\hline Group-1 & \multirow{2}{*}{\multicolumn{2}{|c|}{\begin{tabular}{|c|} 
Primary Strategy \\
3M Preventive \\
Maintenance \\
\end{tabular}}} & \multicolumn{5}{|c|}{ Secondary Strategy } \\
\hline SubSystem & & & \multicolumn{2}{|c|}{$\begin{array}{l}\text { Predictive } \\
\text { Maintenance }\end{array}$} & \multicolumn{2}{|c|}{ Critical Spare } & RCA \\
\hline Mechanical & & 5 & & 5 & & 5 & 4 \\
\hline Electrical & & 2 & & 2 & & 2 & 2 \\
\hline $\begin{array}{l}\text { Instrumentation \& } \\
\text { Communication }\end{array}$ & & 1 & & 1 & & 1 & - \\
\hline \multicolumn{8}{|c|}{ Group2 } \\
\hline Group-2 & \multicolumn{2}{|c|}{\begin{tabular}{|l|} 
Primary Strategy \\
\end{tabular}} & \multicolumn{5}{|c|}{ Secondary Strategy } \\
\hline SubSystem & \multicolumn{2}{|c|}{$\begin{array}{c}\text { 6M Preventive } \\
\text { Maintenance }\end{array}$} & \multicolumn{2}{|c|}{$\begin{array}{c}\text { Predictive } \\
\text { Maintenance }\end{array}$} & \multicolumn{2}{|c|}{ Critical Spare } & RCA \\
\hline Mechanical & & 19 & & 1 & & 1 & 18 \\
\hline Electrical & & 11 & & 2 & & 2 & 2 \\
\hline $\begin{array}{l}\text { Instrumentation \& } \\
\text { Communication } \\
\end{array}$ & & 2 & & 1 & & 1 & - \\
\hline \multicolumn{8}{|c|}{ Group3 } \\
\hline Group-3 & \multicolumn{3}{|c|}{\begin{tabular}{|l|} 
Primary Strategy \\
\end{tabular}} & \multicolumn{4}{|c|}{ Secondary Strategy } \\
\hline SubSystem & \multicolumn{3}{|c|}{\begin{tabular}{|l|} 
1Y Preventive \\
Maintenance
\end{tabular}} & \multicolumn{2}{|c|}{$\begin{array}{l}\text { Predictive } \\
\text { Maintenance }\end{array}$} & \multicolumn{2}{|c|}{ Critical Spare } \\
\hline Mechanical & & & 62 & & 3 & & 3 \\
\hline Electrical & & & 56 & & 2 & & 2 \\
\hline $\begin{array}{l}\text { Instrumentatior } \\
\text { Communication }\end{array}$ & & & 20 & & 2 & & 2 \\
\hline
\end{tabular}

Group4

\begin{tabular}{|l|r|c|}
\hline Group-4 & Primary Strategy & $\begin{array}{c}\text { Secondary } \\
\text { Strategy }\end{array}$ \\
\hline SubSystem & $\begin{array}{r}\text { 2Y Preventive } \\
\text { Maintenance }\end{array}$ & N/A \\
\hline Mechanical & - & \\
\hline Electrical & 117 & \\
\hline $\begin{array}{l}\text { Instrumentation \& } \\
\text { Communication }\end{array}$ & 163 & \\
\hline \multicolumn{2}{|c|}{ Group5 } \\
\hline
\end{tabular}

\begin{tabular}{|l|r|r|}
\hline Group-5 & Primary Strategy & $\begin{array}{c}\text { Secondary } \\
\text { Strategy }\end{array}$ \\
\hline SubSystem & RFT & Rotable Spare \\
\hline Mechanical & 100 & 100 \\
\hline Electrical & - & - \\
\hline $\begin{array}{l}\text { Instrumentation \& } \\
\text { Communication }\end{array}$ & - & - \\
\hline
\end{tabular}

The previous maintenance strategy was annual Preventive Maintenance for all 558 subsystems, whereas in the proposed RBM strategy 138 subsystems are in this category. 280 subsystems are relaxed to 2 Yearly Preventive Maintenance, 100 subsystems with RTF and only 40 subsystems are recommended for 3 or 6 Monthly Preventive Maintenance. These recommendations resulted into substantial cost savings. The average cost of preventive maintenance per year was $\$ 502,200$. It is predicted that the average preventive maintenance cost per year will be $\$ 336,600$ after application of the findings from this research. Some cost will due to new strategies for Predictive Maintenance, Critical Spare, and Rotable Spare.

However, these new strategies will help to mitigate the risks. The increased operational cost of these secondary maintenance strategies is much less compared to the benefits of changes implemented.

It is estimated that, after the implementation of this risk based maintenance strategy the organisation is expected to reduce up to $20 \%$ of the reactive maintenance cost for the sewerage pumping network.

Overall savings per year $=$ Current Preventive Maintenance Cost + Current Reactive Maintenance Cost Predicted Preventive Maintenance Cost - Predictive Maintenance Cost - Reactive Maintenance Cost

$$
=\$ 502,200+\$ 451,980-\$ 336,600-\$ 90,000-
$$
$\$ 361,600$

$=\$ 165,980$

\section{DISCUSSION}

Data from CMMS was available from 01 July-2013. Qualitative assessment was used at the intimal stage of this research. Failure data from CMMS and operational feedback were used in Likelihood and risk analysis. There is need for Capital invest in the first year of implementation of this strategy for reducing the backlogs.

\section{CONCLUSION}

This study proposed the risk based approach to develop a maintenance strategy using findings from a study covering 186 sewerage pumping stations of Townsville Water. This study covered identifying the critical subsystems, analysis and mitigating of the risks of failure of the subsystems. Proposed strategy might be adjustment based on review and used in budgeting cycle based on the asset performance and analysis of costs over the monitoring period. There is significant opportunity for further enhancing strategy by implementing IoT and AI for further enhancing data collection and real time decisionmaking using leading indicators in asset condition for balancing cost, performance and risk.

\section{ACKNOWLEDGMENT}

The authors would like to acknowledge Asset Management Unit of Townsville Water - Townsville City Council for the support and access to data and resource for this project.

\section{REFERENCES}

[1] Chattopadhyay, G., (2016), Issues and challenges of balancing cost, performance and risk in heavy-haul rail asset management, 2016 IEEE International Conference on Industrial Engineering and Engineering Management (IEEM), 521-525.

[2] A Rahman, A. and Chattopadhyay, G.(2007) Optimal service contract policies for outsourcing maintenance service of assets to the service providers, International Journal of Reliability and Applications 8 (2), 183- 197.

[3] Kumar, U. (1998). Maintenance strategies for mechanized and automated mining systems; a reliability and risk analysis 
based approach. Journal of Mines, Metals and Fuels, Annual Review, 343-347.

[4] Chattopadhyay, G \& Kumar, S (2009) 'Parameter Estimation for Rail Degradation Model', International Journal of Performability Engineering, Vol. 5, No. 2, 119-130.

[5] Backlund, F., \& Hannu, J. (2002). Can we make maintenance decisions on risk analysis results? Journal of Quality in Maintenance Engineering, 8(1), 77-91.

[6] Chundhoo, V., Chattopadhyay, G., Gunawan, I. and Yousef I. M. (2017), OEE improvement of thermoforming machines through application of TPM at Tibaldi Australasia, Proceedings of IEEE International Conference on Industrial Engineering and Engineering Management (IEEM2017), Singapore, 10-13 Dec. 2017, 929-933.

[7] Khan, F. I., \& Haddara, M. R. (2004). Risk-based maintenance of ethylene oxide process plant. Journal of Hazardous Materials, A108, 147-159.

[8] Menon, M., Chattopadhyay, G. and Beebe, R., (2018), Decision Support Tools for Preventive Maintenance Intervals and Replacement Decisions of Engineering Assets, Proceedings of IEEE International Conference on Industrial Engineering and Engineering Management (IEEM2018), Bangkok, 16-19 Dec 2018, 257-261.
[9] Krishnasamy, L., Khan, F., \& Haddara, M. (2005) Development of a risk-based maintenance (RBM) strategy for a power-generating plant. Journal of Loss Prevention in the Process Industries, 18, 69-81.

[10] Rouzbeh Abbassi, Jyoti Bhandari, Faisal Khan, Vikram Garaniyaa, Shuhong Chaia (2016). Developing a Quantitative Risk-based Methodology for Maintenance Scheduling Using Bayesian Network. Chemical Engineering Transactions, VOL. 48, 235-240.

[11] Vesely, W. E., Belhadj, M., \& Rezos, J. T. (1993). PRA importance measures for maintenance prioritization applications. Reliability Engineering and System Safety, 43, 307-318.

[12] Jinqiu Hu, Laibin Zhang (2014). Risk based opportunistic maintenance model for complex mechanical systems. Expert Systems with Applications, Volume 41, Issue 6, 3105-3115.

[13] Khan, F. I., \& Haddara, M. R. (2003). Risk-based maintenance (RBM): A quantitative approach for maintenance/inspection scheduling and planning. Journal of Loss Prevention in the Process Industries, 16, 516-573.

[14] Chattopadhyay, G., Reddy, V. and Larsson-Kraik, PO, Decision on economical rail grinding interval for controlling rolling contact fatigue, International Transactions in Operational Research, 12 (6), 545-558. 